\title{
ARENA OLAHRAGA BULUTANGKIS CENGKARENG
}

\author{
Ratna Chandra ${ }^{1)}$, Doddy Yuono ${ }^{2)}$ \\ 1) Program Studi S1 Arsitektur, Fakultas Teknik, Universitas Tarumanagara, ratnacl@yahoo.com \\ 2) Program Studi S1 Arsitektur, Fakultas Teknik, Universitas Tarumanagara, doddyy@ft.untar.ac.id
}

\begin{abstract}
Abstrak
Olahraga bulutangkis Indonesia kini sedang menjadi sorotan berbagai pihak.Prestasinya yang menurun membuat peminat bulutangkis tanah air berkurang. Padahal olahraga bulutangkis merupakan olahraga andalan Indonesia. Dengan menurunnya peminat bulutangkis ini menyebabkan regenerasi atlet menjadi lambat sehingga menambah keterpurukan bulutangkis Indonesia. Proyek ini memiliiki tujuan agar dapat memberikan dampak positif bagi masyarakat luas di kemudian hari.Berikut tujuan pembangunan proyek Arena pertandingan bulutangkis adalah Memberikan fasilitas pertandingan dan latihan bulutangkis ,Sebagai wadah klub klub bulutangkis yang tidak mempunyai fasilitas,Membantu mengajak anak anak usia ideal untuk lebih mengenal olahraga bulutangkis. Metode yang dilakukan dalam penelitian ini adalah metode deskriptif yaitu metode yang menjelaskan dan memaparkan data - data yang telah dikumpulkan, berdasarkan fakta fakta yang ada kemudian dianalisis dan menghasilkan kesimpulan.Data yang diperlukan dalam perencanaan arena bulutangkis adalah data primer dan data sekunder.Konsep saling menindih diterapkan pada bentuk bangunan yang di ambil dari bentuk shuttercock, Stadium terbagi dalam 3 area, yaitu area asrama,area publik dan area pertandingan sehingga tidak mengganggu antar aktifitas. Adanya pengklasifikasian pengunjung dan atlet juga membawa kenyamanan bagi masing masing pihak.Proyek ini menampung 3500 penonton, dengan area pertandingan dengan standart nasional. Untukmemacu dan membangkitkan antusiasme masyarakat terhadap olahraga bulutangkis.
\end{abstract}

Kata kunci: Arsitektur olahraga, Architourism,Bulutangkis, Stadion

\begin{abstract}
Indonesian badminton sport is now in the spotlight of various parties. Its decreasing performance has made the nation's badminton enthusiasts lessen. Even though badminton is Indonesia's flagship sport. With the decline in badminton enthusiasts this causes the regeneration of athletes to be slow, thus adding to the deterioration of Indonesian badminton. The project has a goal to be able to have a positive impact on the wider community in the future. The following is the project development objective of the Badminton Match Arena. It provides facilities and badminton training, as a place for badminton club clubs that do not have facilities. badminton. The method used in this research is descriptive method, which is a method that explains and describes the data that has been collected, based on the facts facts that are then analyzed and produces conclusions. Data needed in planning the arena of badminton is primary data and secondary data. applied to the shape of the building taken from the form of shuttercock, the Stadium is divided into 3 areas, namely the dormitory area, the public area and the match area so as not to interfere between activities. The classification of visitors and athletes also brings comfort to each party. The project accommodates 3500 spectators, with a national standard match area. To stimulate and arouse people's enthusiasm for badminton.
\end{abstract}

Keywords: Architourism, Badminton, Sport Architecture, Stadion

\section{PENDAHULUAN}

Sarana rekreasi dibidang olahraga, yaitu olahraga bulutangkis.Peminat olahraga ini mencangkup seluruh kalangan dari usia 7 tahun sampai usia 60 tahun.Keberadaan proyek stadium bulutangkis yang memenuhi standart regional untuk dapat lebih menunjang prestasi 
prestasi pebulutangkis khususnya yang berada di Jakarta barat. Tujuan proyek ini adalah sebagai wadah pertandingan skala regional, tempat pelatihan dan rekreasi masyarakat dengan standart klasifikasi stadium bulutangkis tipe $B$.

Seiring berjalannya waktu peminat dan prestasi olahraga bulutangkis mulai berkurang. Faktor kemunduran prestasi bulutangkis adalah :

- Fasilitas olahraga bulutangkis kurang memadai dari fasilitas pertandingan, latihan

- Pola latihan tidak berkembang

- Mental atlet yang manja dan mudah frustasi

- Minimnya pembinaan dan pengenalan olahraga bulutangkis sejak dini

- Lambatnya regenerasi atlet

- Kurangnya kompetisi skala nasional dan reginal yang disebabkan minimnya fasilitas dan sponsorship.

- Bulutangkis tidak lagi menjadi olahraga rakyat kerena minimnya fasilitas bulutangkis di masyarakat.

Di Jakarta terdapat sekitar 40 klub klub persatuan bulutangkis yang tersebar di daerah Jakarta Pusat ,Utara,Barat,Timur dan selatan, namun diantara klub klub tersebut yang memiliki fasilitas pendukung suatu pertandingan atau event hanya beberapa saja, diantaranya klub tangkas , Taufik Hidayat arena ,PB Jayaraya. Klub bulutangkis yang lain biasanya menggunakan Gedung Olahraga milik pemerintah yang dipergunakan secara bergantian. Selain masalah tempat pertandingan dan latihan ,permasalahan penting lainnya yang dialami Indonesia yaitu lamanya siklus pergantian atlet yang disebabkan oleh minimnya pengenalan dini terhadap olahraga bulutangkis yang idealnya berada di usia 7-8 tahun.Olahraga bulutangkis mulai dianggap olahraga awam ,karena keterbatasan lahan sehingga menjadi suatu lahan komersil yaitu dibidang penyewaan lapangan. Untuk pertandingan-pertandingan bulutangkis antar klub juga jarang terjadi akibat dari keterbatasan fasilitas pertandingan dan peran sponsor yang kurang mendukung, padahal pertandingan antar klub dapat menjadi titik awal jiwa berkompetisi sejak dini. Gedung olahraga di Jakarta terdapat sekitar 35 gedung olahraga yang dapat dipakai secara umum dengan tarif tertentu namun Gedung olahraga yang memiliki standar dan kapasitas untuk diadakan suatu pertandingan atau event bulutangkis skala regional hanya ada 15.

Proyek ini memiliiki tujuan agar dapat memberikan dampak positif bagi masyarakat luas di kemudian hari.Berikut tujuan pembangunan proyek Arena pertan dingan bulutangkis :

- Memberikan fasilitas pertandingan dan latihan bulutangkis

- Sebagai wadah klub klub bulutangkis yang tidak mempunyai fasilitas

- Membantu mengajak anak anak usia ideal untuk lebih mengenal olahraga bulutangkis

- Memberikan tempat rekreasi terhadap warga sekitar

- Memberikan wadah bagi kaum kaum muda untuk berekspresi dalam bidang olahraga

- Menurunkan tingkat stress dan kejenuhan warga Jakarta

- Memberikan kemudahan untuk berolahraga dan berekreasi

- Menghidupkan kembali rasa social antar warga

- Membantu meningkatkan kualitas hidup masyarakat

- Memberikan wadah terbuka untuk beraktifitas sosial.

\section{METODE}

Metode penelitian dalam menyusun Stadium Bulutangkis ini menggunakan metode analisis dan sintesis, diantaranya:

1. Tahap pengumpulan data dengan mengobservasi lapangan bulutangkis yang sudah ada di sekitar tapak

2. Tahap pengolahan data dengan memilah dan mengelompokan data antara pengguna,event, dan keperluan pertandingan.

3. Tahap Pembahasan dengan metode analisis dan sintesis data dan informasi diolah 
untuk mendapatkan suatu konsep dan program stadion bulutangkis yang akan direncanakan.

4. Hasil dari pembahasan adalah solusi dari kebutuhan dan konsep yang diteliti dan menghasilkan konsep perencanaan yang didukung dengan nilaiArchitourism.

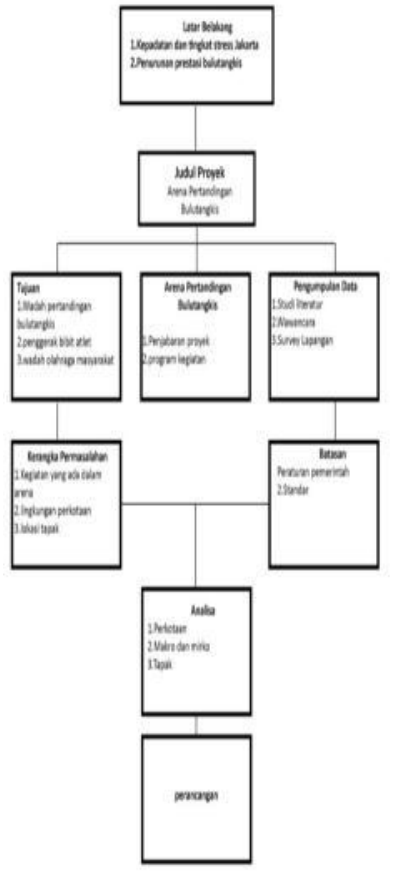

Gambar 1. Sistematika Pembahasan

\section{DISKUSI DAN HASIL}

Konsep stadion yang terletak di Jalan Kamal raya Jakarta barat adalah sebagai wadah pertandingan dan pelatihan olahraga bulutangkis.Stadion diharapkan menjadi ruang terbuka hijau di kawasan cengkareg jakarta barat.

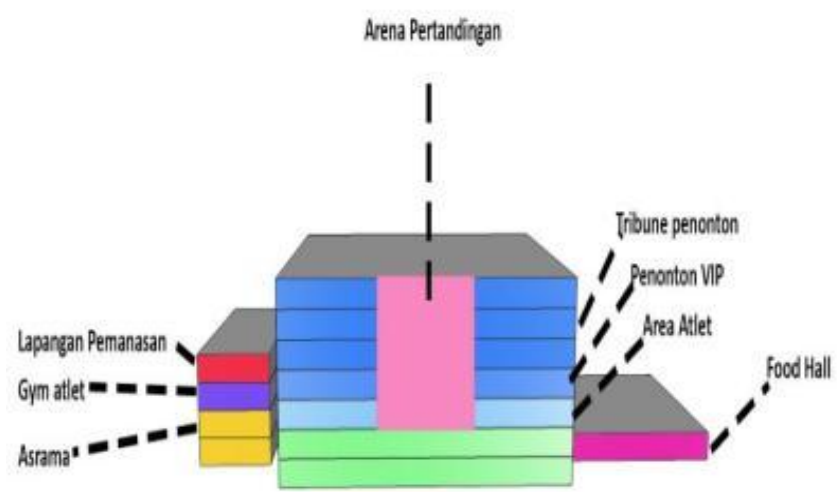

Gambar 2. Gubahan Massa

Pada bagian entrance bangunan pengunjung disambut dengan taman yang besar yang dapat digunakan sebagai arena olahraga bersama.Pembagian antara jalur manusia dengan jalur kendaraan dibuat beda level, sirkulasi manusia dibuat diatas jalur kendaraan untuk memberikan kenyamanan pada pengunjung. Proyek ini dibagi menjadi 3 area yaitu area asrama yang menampung para atlet untuk tinggal dan latihan.Area publik yang berisi area makan, perbelanjaan dan kantor serta area pertandingan yang berada di lantai 2 sampai 4 yang diberikan 2 area didalamnya yaitu area khusus atlet dan area khusus penonton. 


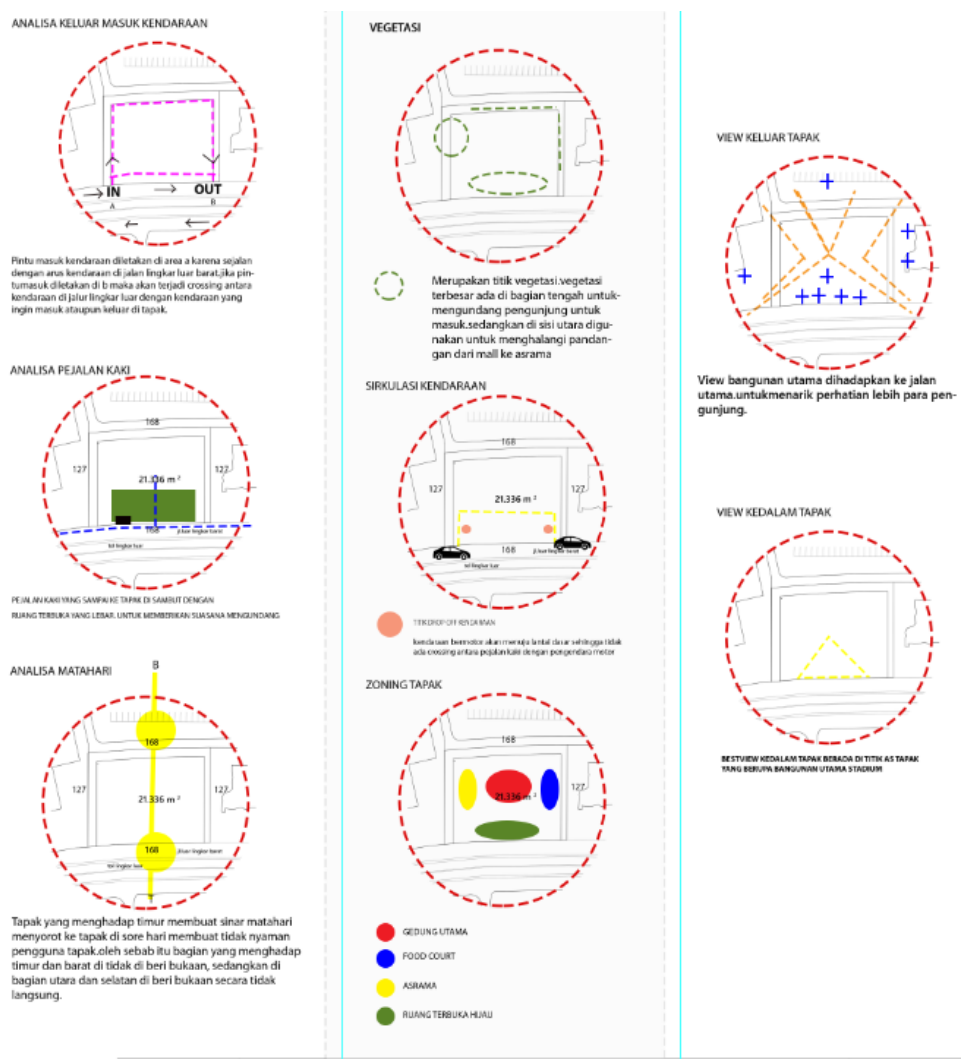

Gambar 3. Analisa Mikro

Bentuk dari bangunan ini adalah persegi panjang yang diambil dari tipologi bangunan stadium bulutangkis.Pada area pertandingan digunakan susunan lapangan yang dinamic dimana susunan lapangan dapat berubah antara latihan,semi final dan final. Konsep ini memberikan ruang yang fleksibel untuk pemain dan penonton.

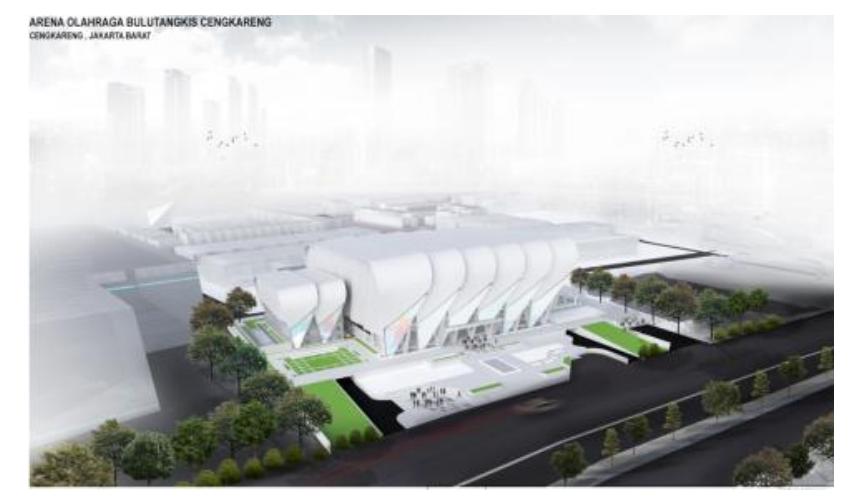

Gambar 4. 3D Eksterior bangunan

Pada lantai 2 stadion digunakan untuk area atlet yang berhubungan langsung dengan lapanganpertandingan dan lapangan pemanasan pada area asrama.

Pada lantai 3 merupakan area penonton reguler dan lantai 3 mezanine merupakan area penonton vip dan area staff pertandingan, area staff diletakan pada area yang jarak pandangnya kurang baik sedangkan pada area jarak pandang yang baik di buat untukpenonton vip. 


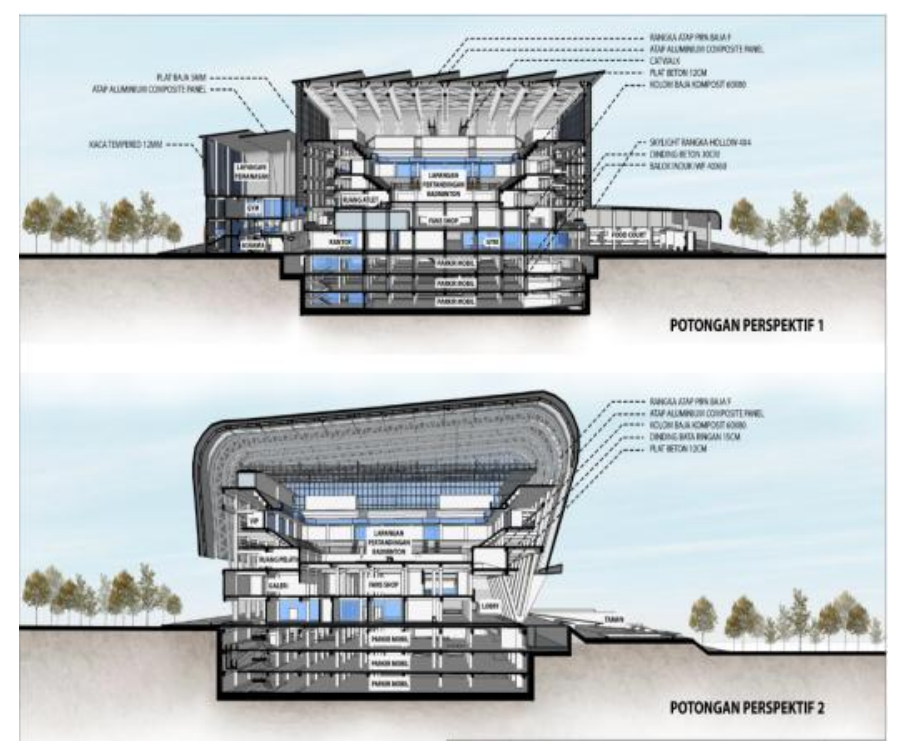

Gambar 5. Potongan Perspektif Bangunan

Program dari proyek ini adalah sebagai wadah pertandingan event official, area rekreasi seperti gallery bulutangkis yang memadukan sport and techologi serta memberikan interaksi antaraatlet dengan masyarakat.

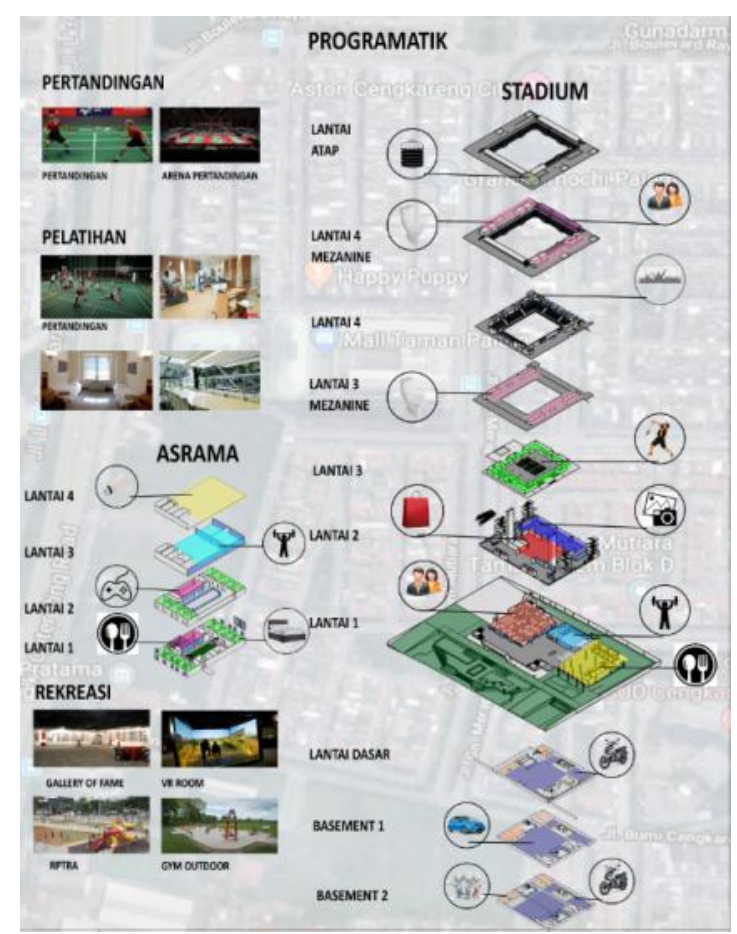

Gambar 6. Programatik Proyek

Bangunan ini menghadap ke arah timur dimana bukaan cahaya di tutup agar tidak mengganggu pada saat atihan danpertandingan berlangsung.

Bangunan yang memiliki konsep saling tumpang tindih yang diambil dari bentuk shuttercock. Sangat cocok diterapkan dalam stadium bulutangkis,selain bentuknya yang menarik dan ikonik, konsep tumpangtindih juga di letakan pada sistem pengudaraan stadium untuk menyaring udara udara dan cahaya alami. 

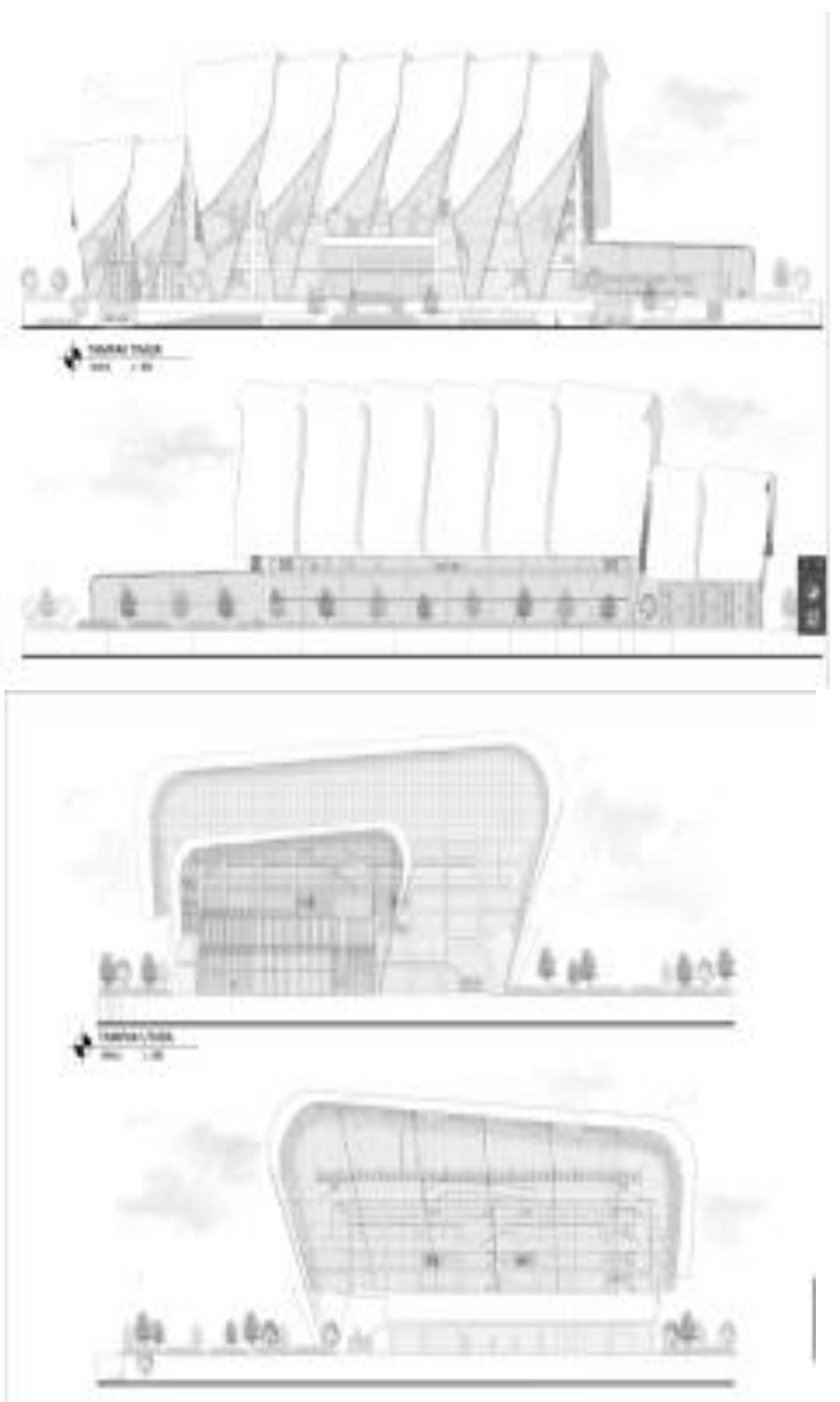

Gambar 7.Tampak Bangunan

Pada bagian interior lapangan pertandingan,proyek ini menggunakan telescopic tribune di lantai lapangan, untuk membuat lapangan menjadi fleksibel. Pada jam latihan dapat memuat 6 lapangan, pada jam semi final dapat menamping 3 lapangan, dan pada jam final dapat menampung 1 lapangan dengan kapasitar penonton maksimal 3500. 


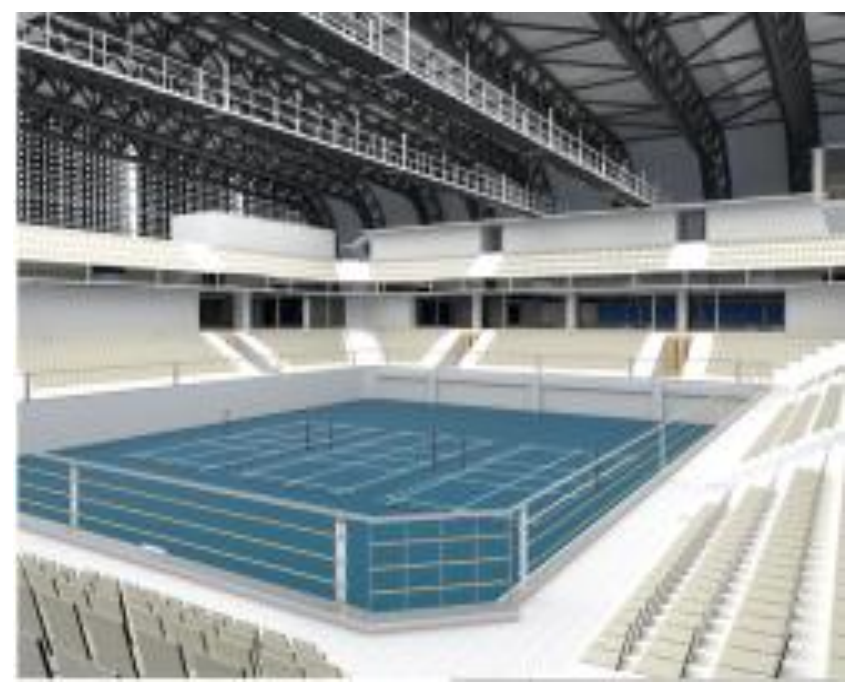

Gambar 8. Interior Lapangan

Pada bagian atap bangunan menggunakan struktur space frame pipa baja dengan bentuk saling tumpeng tindih dengan memasukan difuse pada sela sela atap untuk mencegak cahaya alami masuk dan mengganggu pertandinga. Jika tidak ada pertandingan difuse dapat dibuka dan dapat memberikan cahaya alami, sehingga dapat menghemat penggunaan ac dan listrik.

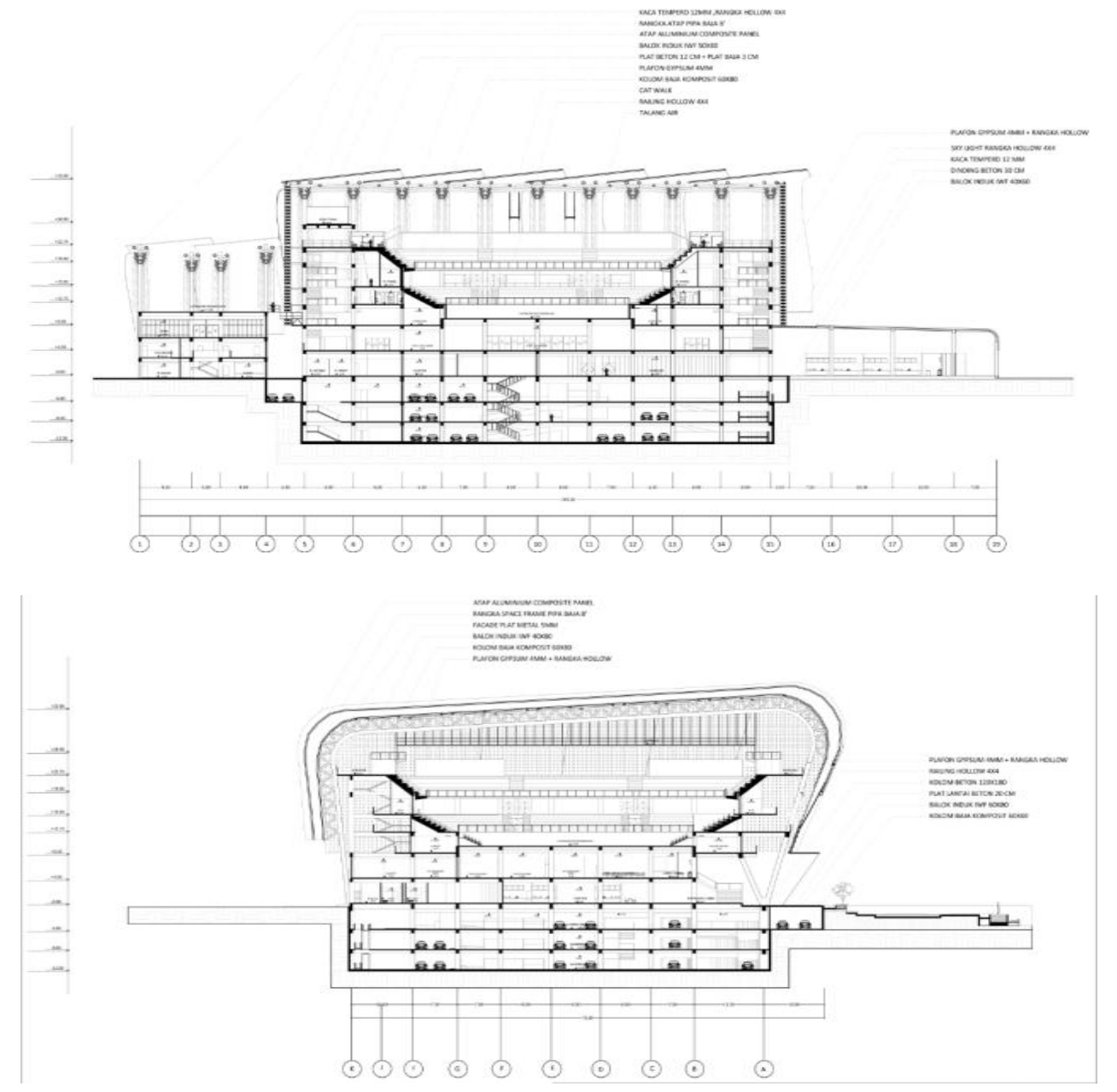

Gambar 9. Potongan Bangunan 


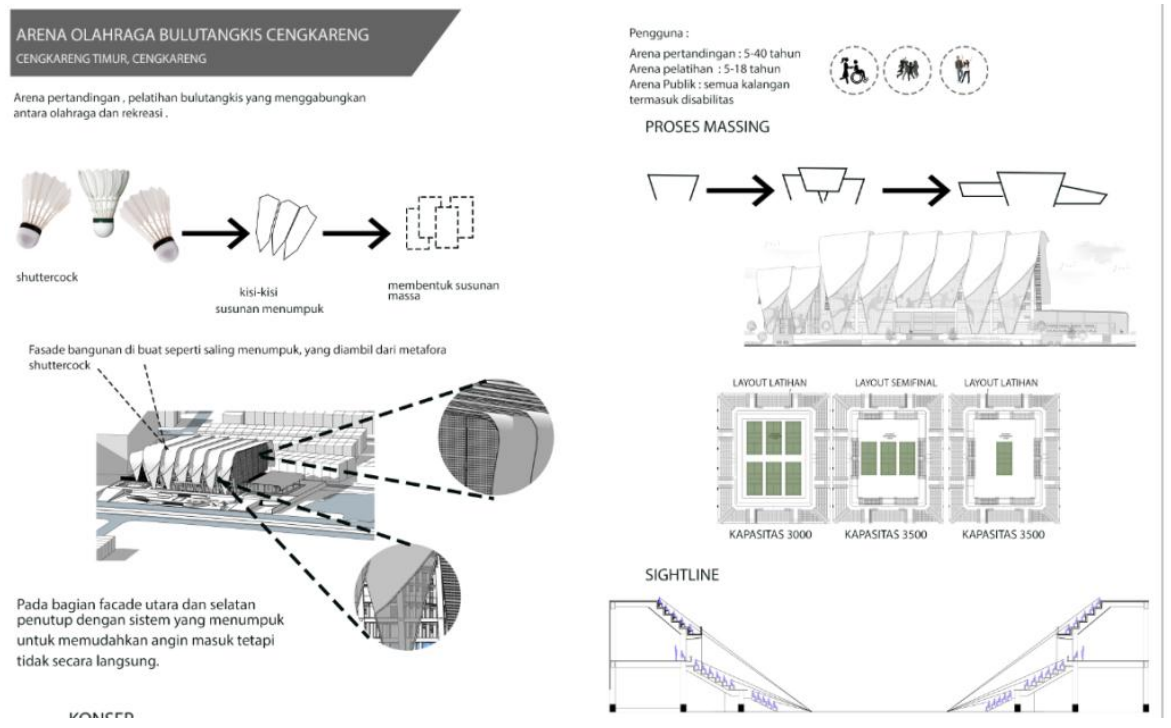

Gambar 10. Konsep Perancangan

\section{KESIMPULAN DAN SARAN}

Stadion bulutangkis ini berkategori B dengan standart nasional dan mempunyai konsep tumpang tindih seperti shuttercock yang di wujudkan dalam bentuk tampak bangunan.Tribun penonton berbentuk persegi panjang seperti tipologi stadion olahraga bulutangkis.Pada bagian depan bangunan diberikan taman yang besar sebagai sarana rekreasi masyarakat dan juga sebagai wadah olahraga masyarakat sekitar yang diharapkan dapat menjadi tujuan alternatif masyarakat dalam berekreasi dan berolahraga.

\section{REFERENSI}

Francis D.K. Ching dan Cassandra Adams. Ilustrasi Konstruksi Bangunan. Jakarta:

Erlangga Neufert, Ernst. (2002). Data Arsitek, Jilid 2 Edisi 33. Jakarta: Erlangga

Badminton Design Guidance Note (Sport England, 2011)

Chen, I-Shen. Lighting Quality in Taiwan's Badminton Courts. Taiwan.

Ardani, P. (2012). https://elib.unikom.ac.id/files/disk1/713/jbptunikompp-gdl-primaardan35632-9-11.uniko-v.pdf, diunduh 12 Juli 2018

Fesihana,2011 Pariwisata Olahraga https://fersyhana.wordpress.com/2011/12/22/45/, diunduh 20 Juli 2018

PB.Djarum,2018. Tips latihan https://www.pbdjarum.org/klub/tips-latihan/, diunduh 12 Juli 2018

Vermacom (2017). Pengertian tujuan dan manfaat olahraga https://www.kata.co.id/Pengertian/Olahraga/1120, diunduh 12 Juli 2018

Sport England's Design Guidance Notes. 2011. http://www.badmintonengland.co.uk, diunduh 20 Juli 2018 